\title{
THE GLOBAL ENVIRONMENT AND THE TOKAIDO SHINKANSEN
}

\author{
Toru Suizu \\ Central Japan Railway Company suizu @ jr-central.co.jp
}

\begin{abstract}
Japanese rail has improved environmental performance while enhancing several sorts of transportation value. This paper describes how rail has conquered this inconsistency with some examples of Tokaido Shinkansen. In addition, the role which railroad should play in the traffic system and the efforts which rail hereafter should make are shown.
\end{abstract}

\section{INTRODUCTION}

Climate change is one of the most important issues in the 21 st century. $\mathrm{CO}_{2}$, one of the principal greenhouse gases, is considered to be a main cause of this phenomenon. The increasing rate of $\mathrm{CO}_{2}$ in the world is 750 ton every second [1], and effective and efficient reducing measure should be taken immediately. In Japan, $\mathrm{CO}_{2}$ emission from transportation section has been increasing sharply. Thus, it is urgently necessary to establish a traffic system to minimize the emission of $\mathrm{CO}_{2}$, taking advantage of the characteristic of each transportation mode.

Rail is so far originally considered to have high environment-friendly qualities.

This paper describes each environmental characteristic of rail, car and air in the passenger section of Japan, as well as their comparison, using the actual results of Tokaido Shinkansen.

\section{THE REASON FOR HIGH ENERGY EFFICIENCY OF RAIL(1)}

It is said that a railroad is a means of transportation with high-energy efficiency. The first reason is generally believed to be its small resistance, but it has not been fully explained. This is mainly because each mode of transportation has different promotion systems, which makes the definitions of resistance also different. In addition, each transportation is produced taking into consideration the optimal speed and optimal transport capacity. Then, it is compared among above-mentioned transportation how each performs at the top speed with full capacity.

Now, at top speed, $R$ is defined as the resistance and $P$ as the power (PS). Pmax is defined as the maximum power (PS), and Vmax as the top speed $(\mathrm{km} / \mathrm{h})$, and $\mathrm{W}$ as the gross weight $(\mathrm{t})$, and $\mathrm{W}$ pmax is maximum load weight $(t)$, then it becomes
R/Wpmax

$=\mathrm{P} / \mathrm{WV} \max \times \mathrm{RV} \max / \mathrm{Pmax} \times \mathrm{W} / \mathrm{Wpmax} \times \mathrm{Pmax} / \mathrm{P}$ Here,

- P/WVmax is so-called Transport Efficiency. This value is designed by G.Gbrielli and von-Karaman as a useful tool for assessment of each transportation mode, (Fig.1) and the smaller in value, the more efficient.

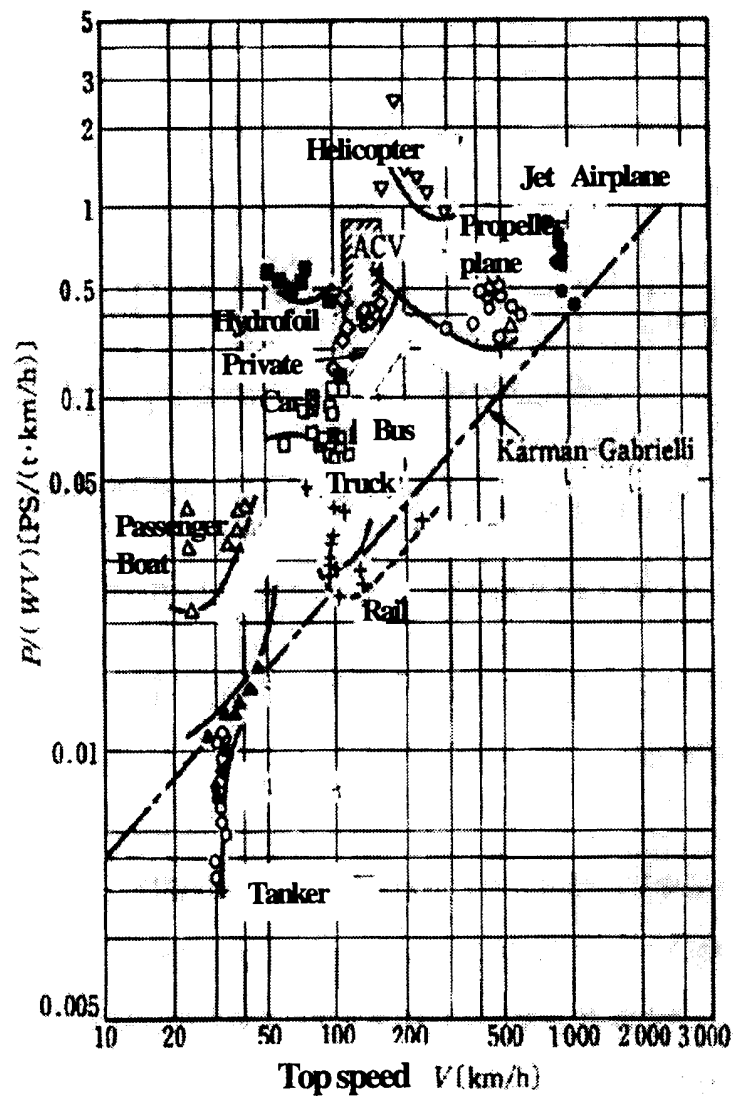

Fig.1 Relation between P/WVmax and top speed [2]

-RVmax/Pmax indicates power efficiency, that is, how efficiently the transportation outputs the power to balance the maximum load at the top speed, and the larger the better. The maximum value for this index is 1.00 .

-W/W pmax is so-called the reciprocal of a payload ratio, naturally the smaller the more efficient.

-P/Pmax is the ratio of output power at the top speed and maximum power, and the larger the better. The maximum value for this index is 1.00 . 
Table1 Energy Efficiency Comparison for each transportation mode

\begin{tabular}{|c|c|c|c|c|c|}
\hline & $\begin{array}{c}\mathrm{P} / \\
\mathrm{WV} \max \end{array}$ & $\begin{array}{c}\mathrm{R} \text { Vmax } \\
/ \mathrm{P} \max \end{array}$ & $\begin{array}{c}\mathrm{Wpmax} \\
/ \mathrm{W}\end{array}$ & $\begin{array}{c}\mathrm{P} / \\
\mathrm{P} \max \end{array}$ & $\begin{array}{c}\mathrm{R} / \\
\text { Wpmax }\end{array}$ \\
\hline Train (Series 211) & 0.04 & 0.27 & 0.35 & 0.35 & 0.07 \\
\hline $\begin{array}{c}\text { Tokaido Sinkansen } \\
\text { (Series 700) }\end{array}$ & 0.10 & 0.60 & 0.11 & 0.91 & 0.56 \\
\hline Private Car [4] & 0.59 & 0.29 & 0.22 & 0.83 & 0.97 \\
\hline $\begin{array}{c}\text { Airplane (Type B747-400 } \\
\text { :for domestic use)[5] }\end{array}$ & 0.28 & 0.20 & 0.15 & 0.20 & 1.92 \\
\hline
\end{tabular}

The calculation example is shown in Table 1. However, this calculation is based on only available data, and does not mean the representative value or average value of each transportation mode. This shows that rail is more efficient than other transportation modes with all parameters. That is, it can be said that rail is a transportation system which demonstrates the capability most effectively.

The second reason why rail has high-energy efficiency is that it has come to use electricity as an energy source instead of former light oil and coal. Fossil fuels such as gasoline and jet fuel, which are worried for their limited use, emit 1.6 times as much $\mathrm{CO}_{2}$ as electricity to produce the same amount of energy. Electricity is indispensable energy for a human life, and is supplied with low and stable cost. Since developments for this have been made frequently, its efficiency is also becoming better every year. While $\mathrm{CO}_{2}$ generating rate per energy unit has been actually reduced by $10 \%$ or more in these ten years, this rate for gasoline or jet fuel has not been changing.

Energy resources, such as sunlight and the bioenergy, are diversified more than ever, and much more reduction of $\mathrm{CO}_{2}$ can be expected, which will highlight the advantage of electricity use more.

Furthermore, as for the latest rail in Japan, regeneration brakes have now been adopted. A regeneration brake revives brake energy by using a motor as a dynamo at braking. Compared with car, which cannot help adding a motor and a storage battery to engine in order to make a regeneration brake run, system is relatively simple and reasonable. Moreover, while, an engine has to be developed by themselves for only exclusive use in the case of car and air the improving results of rail rolling stock can be later applied broadly to industry, such as power electronics technology and microelectronics technology.

As for the train in recent years, these technologies have so far enabled large energy saving. For example, the Seires 300 Shinkansen rolling stock is the first highspeed train to adopt a regeneration brake in the world. The effect of energy saving by regeneration energy reaches to $9 \%$. A resistor which was conventionally needed has become out of necessity any more and lightweight by removing resistors has also contributed to energy saving. In addition, by reduction of air resistance etc., energy saving has reached $27 \%$ on the synthetically same run conditions as the Series 0 . Series 700 is the newest Shinkansen train which has an energy saving rate of $34 \%$. [4]

The transition of power consumption and energy-saving rolling stocks of Tokaido Shinkansen are shown in Fig. 2 Compared with 1990 , power consumption has reduced by $16 \%$ in the fiscal year 2002 , and the effect by energysaving rolling stocks is clear.

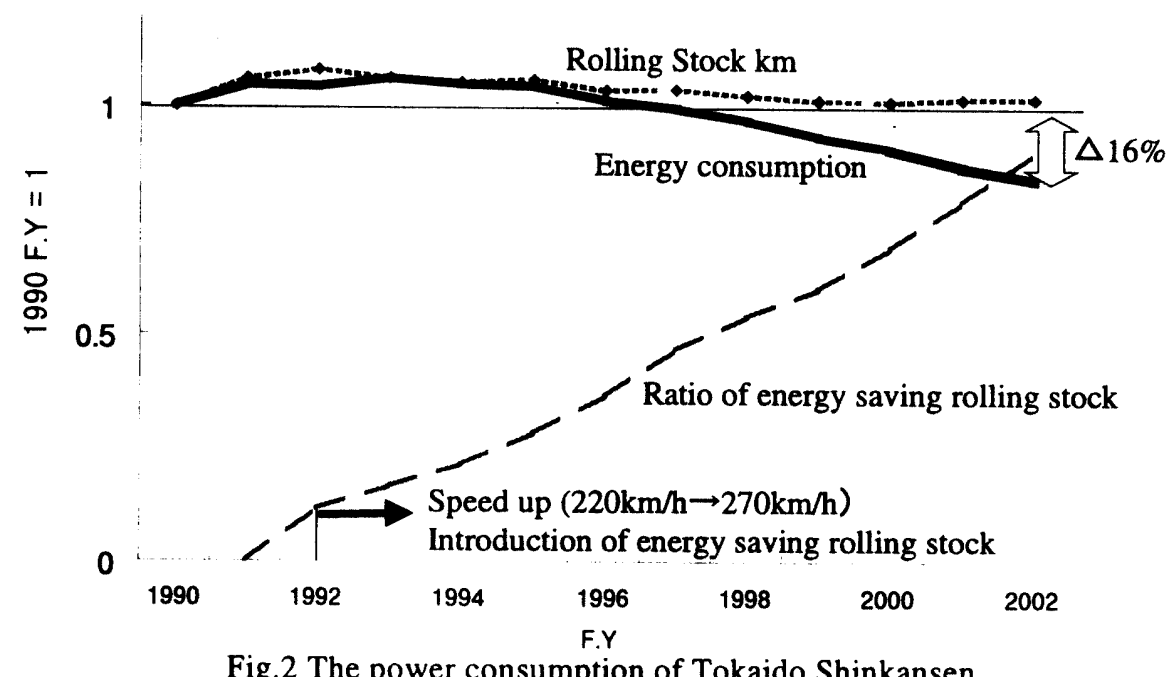

Fig.2 The power consumption of Tokaido Shinkansen 


\section{THE REASON FOR HIGH ENERGY EFFICIENCY OF RAIL (2)}

Indeed energy-saving rolling stocks with lightweight body and regeneration brakes have been introduced recently, it is not enough to reduce the environmental burden.

In Japan, rail has managed software in a body, such as operation management of a railroad, maintenance, and education, excluding hardware, such as vehicles, electric equipment. We thought it important to treat hardware and software as one body, that is, to manage a railroad as a system. [6]

The following chapter states what influence this aspect has on the environment

\section{3-1. EFFECT OF SAFTY AND PUNCTUALITY}

Rail is safe and punctual because rail can use the track exclusively and it is possible to plan train operation in advance. On the other hand, neither car nor air can manage all the operations. Therefore, car and air cannot help consume more energy than necessary for the purpose other than operation. For example car wastes energy no less than $18 \%$ on traffic congestion. [6] The cause of traffic congestion may be various, but it is said that 700,000 tons of $\mathrm{CO}_{2}$ could be reduced with installation of a signal, and formulation and reaction system. Moreover, it is also pointed out that approximately from $6,950,000$ to $7,900,000$ tons of $\mathrm{CO}_{2}$ could be reduced by the measure of promotion of idling stop, ITS, reduction of road construction, etc.[7] This is an immense amount which is equivalent to the amount of discharge from rail in Japan.

Delay of air leads to unnecessary fuel consumption. For example, according to a certain air company, the quantity to be wasted reaches 300,000 tons of $\mathrm{CO}_{2}$ only in a passenger section. [8] Should these conditions be improved, car and air cannot help making efforts to have more efficiency in districted areas, so it may necessarily not be regarded as totally an efficient sysytem.

On the other hand, although Tokaido Shinkansen is most densely operated high speed train in the world, maximum of 12 trains running per hour, the average deviation per train is very small as it is shown in Fig.3. This figure includes the deviation caused by natural disasters, such as a typhoon. What is more, in spite of speed up by operating the "Nozomi Trains", it has been decreasing since 1992 .

Although there is little difference in hardware between before and after privatization in 1987, outstanding difference can be seen on deviation. This is mainly because of the difference in software such as employees' consciousness.

Thus, good hardware is necessary in order to perform planned operation, and it is important to maintain the software which can operate and manage the hardware.

\section{3-2. EFFECT BY OPERATION}

In order to improve the energy efficiency of transportation, it is necessary to flexibly correspond to the change of passengers on demand. As rail is usually operated connecting two or more rolling stocks, when changing operation numbers or train capacity, railroad is easy to change more flexibly than car, bus, airplane, which are based on solo vehicle operation. However, since these measures need large amount of investment, demand should be estimated precisely for the long future.

When demand is increasing, train can manage by increasing capacity rate to some extent instead of increasing operation frequency. Moreover, when newly investing, rail allows it easy to reduce environmental burden by introducing newest equipment. The actual

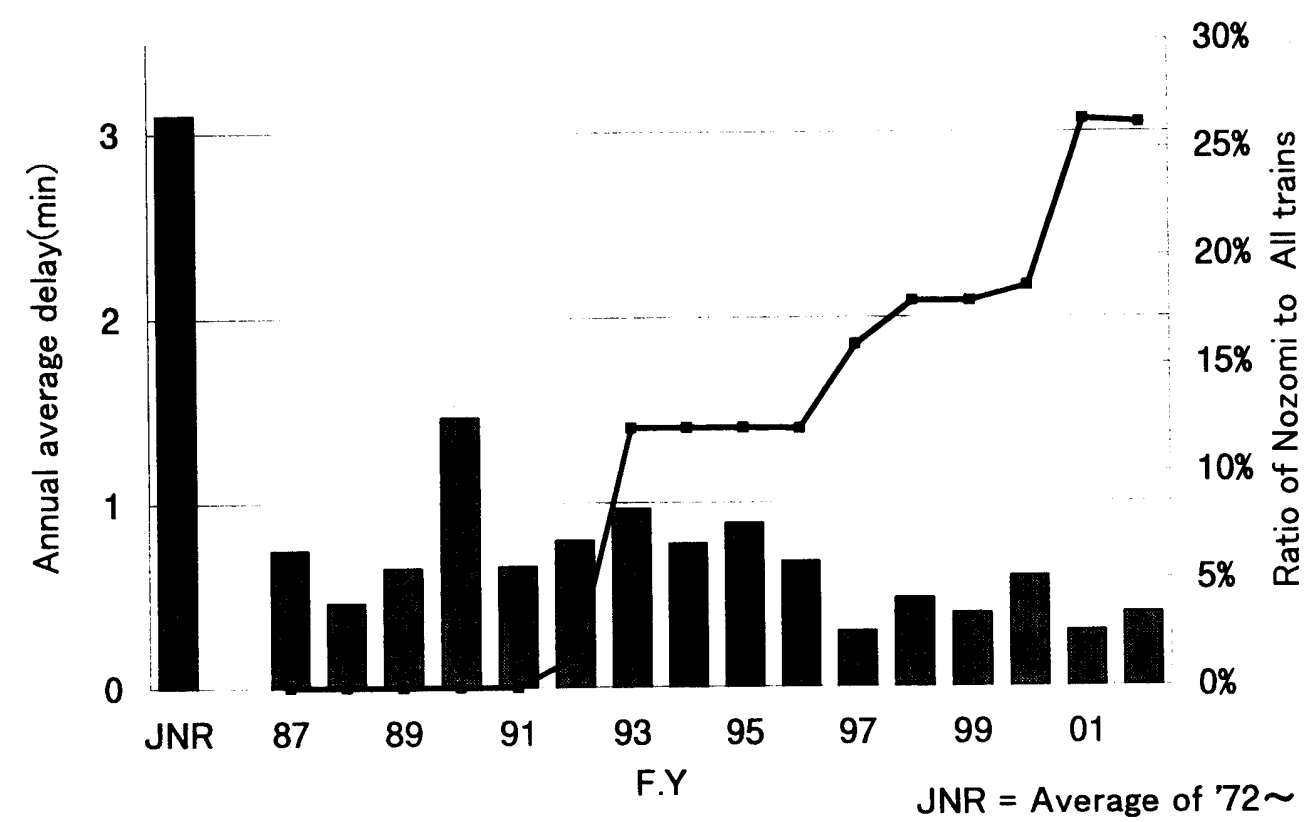

Fig. 3 The average deviation per train of Tokaido Shinkansen, and numbers of "Nozomi Trains" 
Table2 Change of Energy Efficiency (F.Y1990=100)

\begin{tabular}{|l|c|c|c|c|}
\hline & Railroad & Private car & $\begin{array}{c}\text { Airplane } \\
\text { (Domestic) }\end{array}$ & $\begin{array}{c}\text { Tokaido shinkansen } \\
\text { ( ); F.Y 2002 }\end{array}$ \\
\hline Energy Consumption(J) & 102 & 154 & 157 & $87(80)$ \\
\hline Traffic volume(person-km) & 99 & 130 & 154 & $96 \quad(96)$ \\
\hline $\begin{array}{l}\text { Energy Efficiency } \\
\text { (J/person-km) }\end{array}$ & 103 & 119 & 102 & $90 \quad(83)$ \\
\hline
\end{tabular}

comparative result of energy efficiency in 2000 fiscal year of private car, air, and Tokaido Shinkansen is shown in Table 2. Indeed car and air is increasing in traffic volume and this is why they seem to improve energy efficiency (energy/person-km), but car got worse by $19 \%$ and air by $2 \%$. On the other hand, rail got worse $3 \%$, in spite of decreasing in traffic volume. Though each transportation modes have improved by introduction of energy-saving vehicles, all transportation resulted in getting worse. The reason Tokaido Shinkansen improve the energy efficiency is that we have planned operation according to transportation demand, as well as the introduction of energy-saving rolling stocks.

To summarize above-mentioned results, the transition of total $\mathrm{CO}_{2}$ emissions and $\mathrm{CO}_{2}$ emissions per person-km from each transportation mode are shown in a figure 4 and 5 .

While $\mathrm{CO}_{2}$ emission from rail is decreasing, that from car and air has increased by $50 \%$ or more compared with 1990 fiscal year. Now, airplane especially discharges $\mathrm{CO}_{2}$ more than rail by no less than $30 \%$ of rail. (Fig.4) As shown in Fig. 5, although Tokaido Shinkansen is a

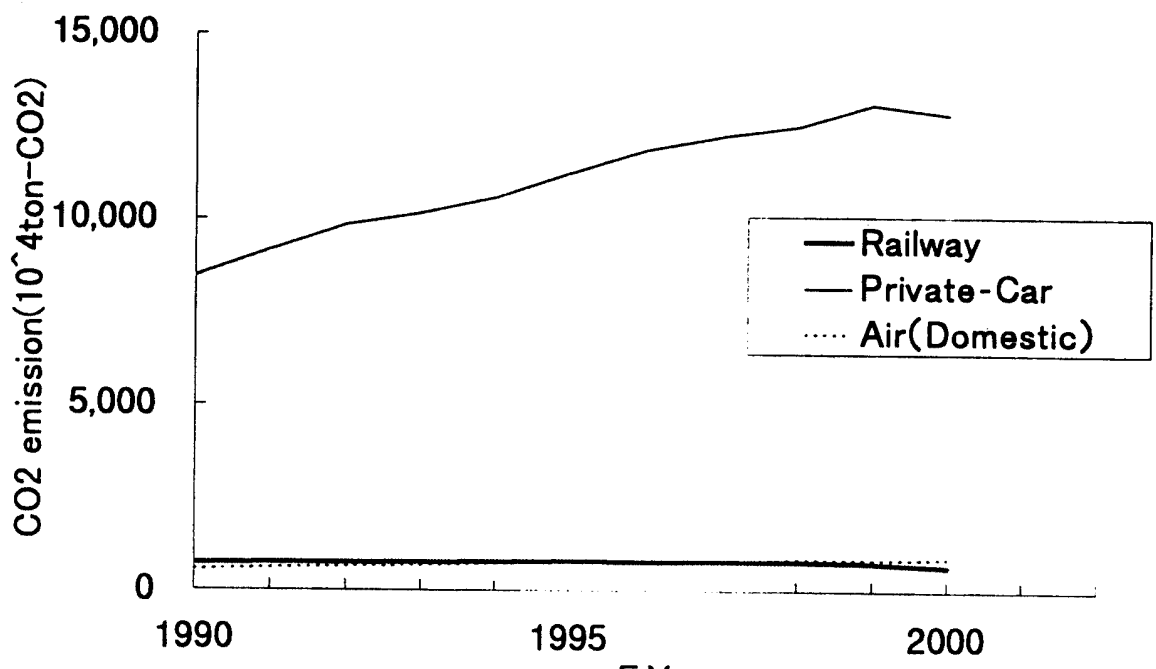

Fig.4 The transition of total $\mathrm{CO}_{2}$ emissi $F_{\mathrm{n}} Y_{\text {from each transportation mode }}$

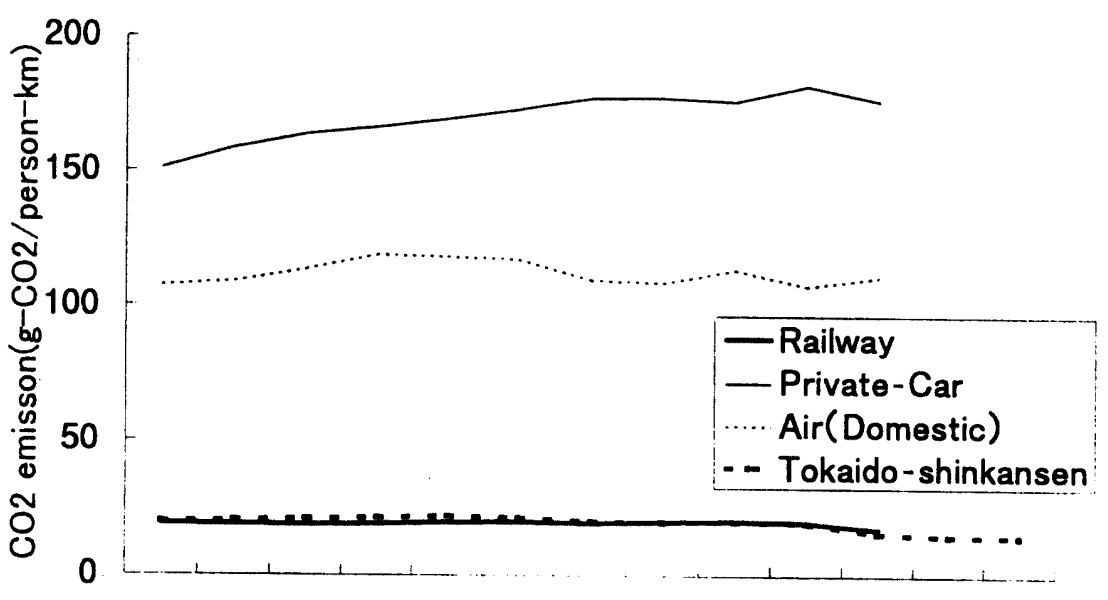

Fig.5 Trantsiln $\mathrm{n}$ of $\mathrm{CO}_{2}$ emissions perpeps.pn-km from each 2000 transportation mode 
high-speed train, its $\mathrm{CO}_{2}$ emission per person-km is less than the average value of rail in Japan. Thus, the reason why rail has been able to reduce the environmental burden while enhancing its transportation value is that we have succeeded in investment as planned for more than 10 years as well as we have managed rail as one body. Neither car nor air could have reached such a result.

\section{OTHER MERITS OF RAIL}

However excellent rail may be in environmental performance, it is meaningless if rail is not selected by passengers. Moreover, if a company were not managed well, it would finally decrease social profits, because the fare might be risen and the company might be subsidized.

When railroad needs to be competitive against other transportation, speed up, increase in operation numbers, etc. will cause more energy consumption and vast amount of investment. It is very difficult to reduce environmental burden while enhancing transportation value and cutting cost. The following below introduces to the reduction in environmental burden and cutting cost of Tokaido Shinkansen.

As for Tokaido Shinkansen, all cars will be capable of top speed of $270 \mathrm{~km} / \mathrm{h}$ and capacity of 1,323 seats this October. Generally speed up of a train causes more power consumption and cost increase. However, the average power consumption of one train is estimated to decrease by about $7 \%$ to about $17 \%$ on the trial calculation. This effect is large enough to reduce electric power cost by as much as 5 billion yen every year. In addition, we can operate the same as the condition with 11 trainsets less than now.
Although energy-saving train is more expensive than a previous one by approximately $20 \%$, it is recoverable with reduction of power consumption and the reducing number of train sets in several years.

Moreover, also as for maintenance, the sort and number of spare parts can be reduced by making work more efficient. Thus, in order to make social profits, rail needs to reduce environmental burden, reducing cost by energy saving or laborsaving.

\section{HARMONY WITH OTHER TRANSPORTATION}

G.Bouladon[11]-by travel time to distance, G.Gabrielli, von-karman[10], and Dr. Akagi[11]-by unit power and a ratio output - they have pointed out that there exists an optimal transportation according to the speed region.

(Fig.6)

From a viewpoint of global warming prevention, establishment of traffic system is desired which carries out the maximum practical use of the characteristic of each means of transportation. If a fare, boarding time, and convenience are similar, it is important that a means of transportation with smaller environmental burden should be chosen. For example, between Tokyo - Osaka, the Shinkansen emits $\mathrm{CO}_{2} 1 / 10$ of an airplane. A fare and boarding time are also equivalent and the Shinkansen is superior in convenience. When all airplane transportation of this section were substituted by the Shinkansen, at least 370,000 tons of $\mathrm{CO}_{2}$ could be certainly cut down in one year. In Japan the passenger share of rail is $27 \%$ now. Consequently, $\mathrm{CO}_{2}$ emission per person-km in passenger transport is smaller than that in EU countries by $20 \%$ or

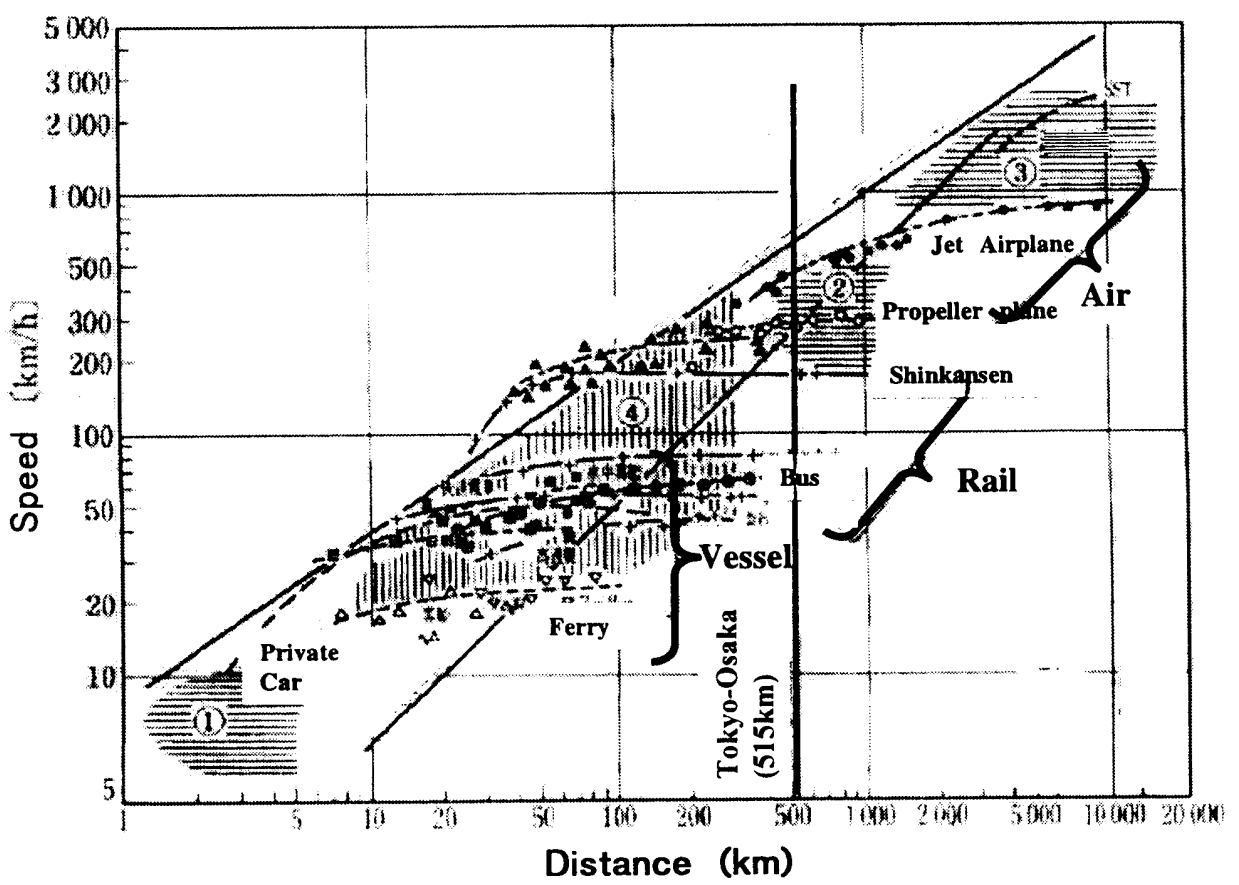

Fig. 6 Suitable field of various means of transportation 
more.

But if the share of rail were the same grade as $\mathrm{EU}(8 \%)$, approximately 13 million tons or more of $\mathrm{CO}_{2}$ would increase, and this is equivalent to $\mathrm{CO}_{2}$ emission of Portugal.[12]

Although such an effect is seldom focused in Japan, it is one of the important factors in Europe to compare the efficiency of transportation mode as external expense.

Here quote relevant phrases below from the white paper of the European Commission. [13]

\section{"-The growth in road and air traffic must therefore be} brought under control, and other environmentally friendly modes given the means to become competitive alternatives. Intermodality with rail must produce significant capacity gains by transforming competition between rail and air into complementary between the two modes, with high-speed train connections between cities. We can no longer think of maintaining air links to destinations for where there is a competitive high-speed rail alternative. In this way, capacity could be transferred to routes where no high-speed rail service exists. -"

Statements with specific figures continue as follows, "for rail to increase its market share of passenger traffic from 6 to 10 ; a $50 \%$ gain in energy efficiency; a $50 \%$ reduction in emissions of pollutants"

Each European country has now been constructing rail, especially high speed one as a national policy. The result is about to appear, as rail traffic volume has been increasing and car traffic has been decreasing in Britain, Germany, and France.

It is said that Japan will be paying the most to reduce $\mathrm{CO}_{2}$ in the world, which leads to weaken the competence and social profits of Japan.

In Japan $\mathrm{CO}_{2}$ emission has been increasing only in the transportation section. It is a serious duty of a transportation section to reduce $\mathrm{CO}_{2}$ efficiently at low cost. In addition to integrated management treating railroad as a system, JR Central could enhance transportation value by having made an investment over the long period of time of 10 years or more as planned while reducing environmental burden. It is important the whole transportation section of Japan should make efforts to reduce environmental burden as ours. It is required to build transportation system in which each means of transportation functions, taking advantage of the individual characteristic. In addition, both the political efforts with long-term views and the efforts of each transportation entrepreneur are hereafter indispensable.

\section{REFERENCE}

AND TRANSPORT.: THE SURVEY ON TRANSPORT ENERGY

Katuhisa Nasukawa, Yoshitaka Miyashita, Mitsunori Shiokawa $\therefore$ Efficiency Tests for Running, pp28

Japan Air Line's Homepage

Yoshiyasu Hagiwara.: The energy saving efficiency of Tokaido Shinkansen, JREA Vo45 No8(2002)

The Energy Conservation Center, Japan HP

Tsutomu Morimura.:The Course of Technical Progress toward Increasing Speeds of All Tokaido Shinkansen Trains to $270 \mathrm{~km} / \mathrm{h}$,JREA Vo46 No5(2003)

7] The New Climate Cange Policy Programme.: Decision By The Global Worming Prevention Headquarters Government Of Japan

Lufthansa Mail News(2000/8/3)

Boulandon,G.:Techinological

Applied to Transport,Future(1970)

Forecasting

Gabrielli, G. and von Karman, T.:What price speed? Mech. Eng. 72, pp775-781. (1950)

Shinsuke Akagi.:Transportation Vehicles Enginnreing -Social Demands and Technology -(1995)

Marland, Gregg, Tom Boden, and Bob Andres.

"National $\mathrm{CO}_{2}$ Emissions from Fossil-Fuel Burning, Cement Manufacture, and Gas Flaring: 1751-1998, July 31, 2001," Carbon Dioxide Information Analysis Center, Oak Ridge National Laboratory. EUROPEAN COMMISSION.: WHITE PAPER European transport policy for 2010:time to decide 